\title{
Esophagus and Esophagogastric Junction Cancer Pathologic Distant Metastasis TNM Finding v7
}

National Cancer Institute

\section{Source}

National Cancer Institute. Esophagus and Esophagogastric Junction Cancer Pathologic

Distant Metastasis TNM Finding V7. NCI Thesaurus. Code C89743.

A pathologic finding about one or more characteristics of esophagus and esophagogastric junction cancer, following the rules of the TNM AJCC V7 classification system as they pertain to distant metastases. There is no pathologic M0 for esophagus and esophagogastric junction cancer. 